\title{
A Behavior Genetic Investigation of the Relationship Between Leadership and Personality
}

\author{
Andrew M. Johnson', Philip A. Vernon ${ }^{2}$, Julie Aitken Harris ${ }^{3}$, and Kerry L. Jang ${ }^{4}$ \\ ' Faculty of Health Sciences, The University of Western Ontario, London, Ontario, Canada \\ ${ }^{2}$ Department of Psychology, The University of Western Ontario, London, Ontario, Canada \\ ${ }^{3}$ Administrative and Commercial Studies Program, Faculty of Social Sciences, The University of Western Ontario, London, Ontario, Canada \\ ${ }^{4}$ Department of Psychiatry, University of British Columbia, Vancouver, British Columbia, Canada
}

P henotypic research on leadership style has long considered the importance of individual differences in personality when identifying the behaviors associated with good leaders. Although leadership and many personality traits have been separately shown to be heritable, these constructs have not been examined with genetically informative data to identify common sources of heritability in the two domains. A logical extension to current research, therefore, is to examine the extent to which factors of personality are predictive of leadership dimensions and the extent to which unique genetic contributions to the relationship between personality and leadership style may be identified. Adult twin pairs (183 MZ and 64 same-sex DZ) completed the Multifactor Leadership Questionnaire (MLQ) and the Personality Research Form (PRF). Univariate analyses indicated that both leadership factors (transformational and transactional leadership) and all five of the "Big Five" factors (openness, conscientiousness, extraversion, disagreeableness, and neuroticism) were best fit by genetic models. Multivariate genetic analyses suggest that transformational leadership shows a statistically significant positive genetic correlation with conscientiousness, extraversion, and openness to experience. Transactional leadership shows a significant negative genetic correlation with conscientiousness and extraversion, and a significant positive genetic correlation with disagreeableness. These results underscore the importance of conscientiousness and extraversion in predicting leadership style, and illustrate important differences between transformational and transactional leaders.

One of the more enduring models of leadership involves a distinction between transactional leadership, in which the leader offers promises of rewards and benefits in exchange for loyalty, and transformational leadership, in which followers are motivated to produce more than what is asked for by the leader (Burns, 1978). Although Burns (1978) originally proposed that transformational leadership and transactional leadership are orthogonal dimensions of leadership style, Bass (1985) has suggested that some transformational leaders utilize transactional strategies to a certain degree - in other words, the transformational leader may use transactional strategies to increase their success with followers.

Early leadership research began, however, with the intention of distinguishing those with leadership ability from those without, on the basis of personality traits. To this end, researchers have compiled lists of traits associated with leadership, typically through observations of the characteristics of publicly visible leaders (Bass, 1990; Stogdill, 1948). More recently, research investigating the relationship between omnibus personality dimensions and leadership style (e.g., Keller, 1999; Silverthorne, 2001) has suggested a significant contribution from all of the factors in the "Big Five" model of personality (openness to experience, conscientiousness, extraversion, agreeableness, and neuroticism). The question as to whether leaders are "born or made", however, is one that dates back to the "great man" theory of William James (1880, 1890), and remains an issue that has been infrequently addressed with systematic genetic methodology (Johnson et al., 1998).

The majority of twin studies have demonstrated moderate to large genetic contributions to most personality dimensions (Loehlin, 1992; Plomin et al., 1990). On average, individual differences in personality have been found to be approximately $40 \%$ heritable (Plomin et al., 1990). A recent behavior genetic investigation has demonstrated that leadership is similarly heritable, with most dimensions of leadership style showing a primarily genetic origin (Johnson et al., 1998). Johnson et al. (1998) further suggested

Address for correspondence: Andrew M. Johnson, Faculty of Health Sciences, The University of Western Ontario, London, Ontario, Canada N6A 3K7. Email: ajohnson@uwo.ca 
that a higher-order factor resembling transformational leadership demonstrated higher genetic determination $(59 \%)$ than did a higher-order factor resembling transactional leadership (48\%), and that most of the variables studied shared substantial genetic covariance, suggesting a large overlap of the underlying genes responsible for the leadership dimensions.

The demonstrated heritability of both omnibus personality and leadership suggests, therefore, an important extension to both research domains: to what extent does leadership style share common sources of genetic variability with personality? Furthermore, do transactional and transformational leadership domains differ in the extent to which they share genetic variance with dimensions of omnibus personality? The present study was designed to address these questions.

\section{$\overline{\text { Method }}$ \\ Participants}

Participants were part of a large behavior genetic investigation, spanning multiple personality constructs (Johnson et al., 1998; Vernon et al., 1999). The subjects were 247 adult twin pairs: 183 pairs of monozygotic (MZ) twins (149 female pairs, mean age $=45.1$ years, $S D=16.5 ; 34$ male pairs, mean age $=45.1$ years, $S D=15.8)$, and 64 same-sex dizygotic (DZ) twin pairs (55 female pairs, mean age $=42.8$ years, $S D=17.6 ; 9$ male pairs, mean age $=33.9$ years, $S D=8.9$ ).

\section{Materials and Procedure}

Twin pairs were recruited through newspaper advertisements and by word of mouth through local multiple birth associations. Participants were mailed a questionnaire package that included two self-report questionnaires assessing different facets of leadership behavior: the Multifactor Leadership Questionnaire (Bass \& Avolio, 1991), and the Personality Research Form (Jackson, 1987).

The Multifactor Leadership Questionnaire (MLQ) is an 80 -item measure requiring subjects to rate the applicability of items to their own behavior, using a 5point scale. The test consists of nine measures of leadership behavior: attributed charisma, idealized influence, inspirational motivation, intellectual stimulation, individualized consideration, contingent reward, active management-by-exception, passive management-by exception, and laissez-faire leadership. These scales are described in detail by Johnson et al. (1998), and a good description of the construction method and assumptions underlying the MLQ is presented in Avolio et al. (1995).

The Personality Research Form (PRF) is a 352-item personality inventory that requires individuals to make "me" and "not me" decisions to statements about their personality. Twenty trait scores are calculated from the PRF items, and the measure has been shown to represent a sizable proportion of the total domain of personality (Jackson, 1987). The 20 trait scales are: abasement, achievement, affiliation, aggression, autonomy, change, cognitive structure, defendence, dominance, endurance, exhibition, harm avoidance, impulsivity, nurturance, order, play, sentience, social recognition, succorance, and understanding. Jackson (1987) provides complete information on norming and validity.

Subjects also completed a zygosity questionnaire (Nichols \& Bilbro, 1966), which has a reported accuracy of $93 \%$ in comparison with the results of blood-typing (Kasriel \& Eaves, 1976).

\section{Results}

\section{Preliminary Analyses}

Means were computed for each raw scale based on the whole sample and within each kinship group. A one-way analysis of variance was performed on each variable to compare the means between kinship groups, using each member of each twin dyad as an independent replication. None of the variables demonstrated a significant mean difference between $\mathrm{MZ}$ and DZ twins and tests for heterogeneity of variance indicated that there were no significant differences in variances between kinships.

\section{Factor Analyses}

Because the MLQ was designed to tap multiple facets of a two-dimensional factor space (i.e., transformational and transactional leadership), higher order factors were extracted from a principal components analysis of the MLQ. To identify the extent to which these factors are correlated, direct oblimin rotation was used to estimate simple structure in each of two extracted factors. As these factors were not significantly correlated, the principal components extraction was rotated with a varimax algorithm to facilitate interpretation. The resulting varimax-rotated factor matrix is presented in Table 1 . Two factors were extracted, based on an examination of the scree plot. The first rotated factor of the solution obtained in this fashion accounts for $50.9 \%$ of the total variance in the sample space, and is identifiable as transformational leadership. The second rotated factor of the solution accounts for $20.9 \%$ of the variance, and is identifiable as transactional leadership. This factor solution (and this labeling) is congruent with previously published results (Avolio et al., 1995; Bass, 1985; Bass \& Avolio, 1991). The regression method of factor score generation was used to create factor scores for both leadership dimensions.

As the PRF does not explicitly reduce to the five scales of personality encompassed by the five-factor model, a principal components factor analysis was conducted on the scales of the PRF, and an examination of the scree plot suggested the extraction of five factors. Using a similar method to that employed with the MLQ, the five factors extracted from the PRF were rotated to an approximation of simple structure, 
using direct oblimin rotation. No significant correlations between the factors were observed following oblimin rotation, and so a varimax rotation was applied to the principal components extraction to facilitate interpretation. The resulting rotated factor matrix is presented in Table 2. Factors one and two appear to represent conscientiousness $(13.4 \%$ of the variance in the solution) and extraversion $(13.3 \%$ of the variance in the solution), respectively. Although factors three and four are somewhat more difficult to interpret, they appear to align reasonably well with the "Big Five" factors agreeableness (negative direction) and neuroticism, respectively, with factor three accounting for $11.2 \%$ of the variance and factor four accounting for $11.0 \%$ of the variance. Finally, factor five accounts for $10.9 \%$ of the variance, and appears to represent openness to experience. The regression method of factor score generation was used to create factor scores for all five personality dimensions.

To examine the effects of age and sex on the variables used in the multivariate genetic analyses, a direct-entry multiple regression procedure was used to predict each factor score from age and sex. The $\mathrm{R}^{2}$ adj value was quite small for both transactional $\left(\mathrm{R}^{2}\right.$ adj $=$ $\left.0.003, \mathrm{r}_{\mathrm{age}}=0.00, \mathrm{r}_{\mathrm{sex}}=-.17\right)$ and transformational leadership $\left(R_{\text {adj }}^{2}=.00, r_{\text {age }}=.05, r_{\text {sex }}=.04\right)$. Multiple correlations were only slightly higher for the personality dimensions, with disagreeableness demonstrating the largest prediction from age and $\operatorname{sex}\left(R_{\text {adj }}^{2}=.13, r_{\text {age }}\right.$ $\left.=-.31, r_{\text {sex }}=-.21\right)$, followed by neuroticism $\left(R_{\text {adj }}^{2}=\right.$ $\left..07, r_{\text {age }}=.14, r_{\text {sex }}=.24\right)$, openness to experience $\left(R_{\text {adj }}^{2}\right.$

\section{Table 1}

Varimax Rotation of Principal Components Solution for the MLO

\begin{tabular}{lcc}
\hline & I & II \\
\hline Attributed Charisma & .84 & -.13 \\
Idealized Influence & .88 & -.06 \\
Inspirational Motivation & .88 & -.22 \\
Intellectual Stimulation & .82 & -.00 \\
Individualized Consideration & .87 & -.16 \\
Contingent Reward & .79 & .18 \\
Management-by-Exception, Active & .33 & .71 \\
Management-by-Exception, Passive & -.15 & .84 \\
Laissez-Faire & -.38 & .74 \\
Eigenvalues & 4.58 & 1.88 \\
\hline Note: I: $\quad$ Transformational Leadership & & \\
$\quad$ II: Transactional Leadership & &
\end{tabular}

Table 2

Varimax Rotation of Principal Components Solution for the PRF

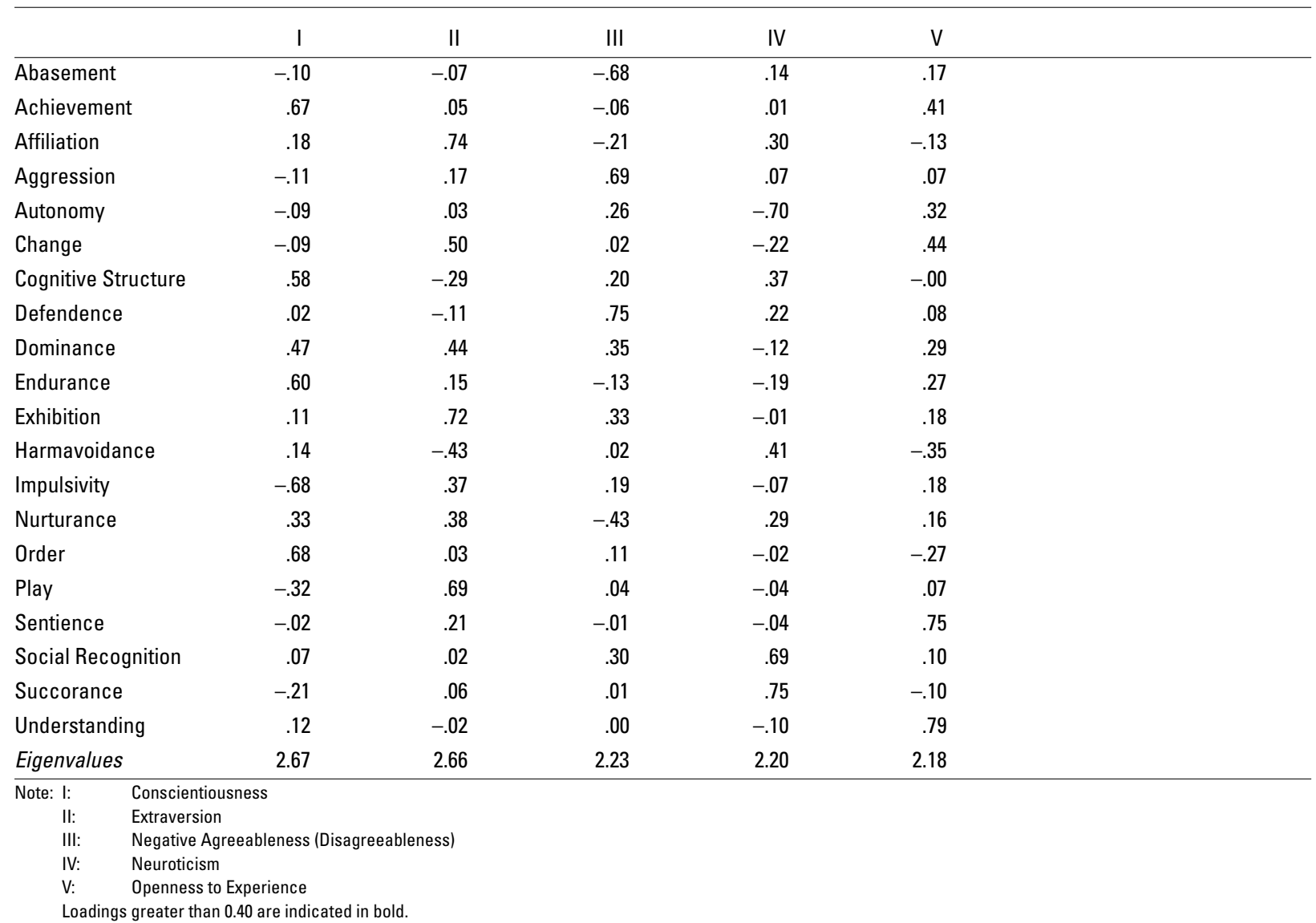


$\left.=.05, r_{\text {age }}=-.22, r_{\text {sex }}=.002\right)$, conscientiousness $\left(R_{\text {adj }}^{2}=\right.$ $\left..02, r_{\text {age }}=.15, r_{\text {sex }}=.07\right)$, and extraversion $\left(R_{\text {adi }}^{2}=.01\right.$, $\left.r_{\text {age }}=-.13, r_{\text {sex }}=-.04\right)$. As recommended by McGue and Bouchard (1984), potentially confounding influences of age and sex were eliminated by creating completely standardized residual scores from these regressions. All further analyses were based on these transformed variables.

\section{Univariate Genetic Analyses}

Johnson et al. (1998) presented univariate genetic analyses for the subscales of the MLQ in this sample, reporting heritable components for all but two of the MLQ subscales (both of which loaded on the transactional leadership dimension). Univariate genetic analyses for the scales of the PRF, and the factor scores on the MLQ and the PRF were conducted using Mx (Neale, 1997). For all variables, a full ACE model was fit first, to determine the proportion of variance that is attributable to additive genetic effects
(A), common environmental effects (C), and specific environmental effects (E). This full model was then systematically decomposed into two models, AE and CE, comprising only two sources of variation each. The final model fit to the data was an E model, comprising only one source of variation, namely specific environmental variance. To determine which model afforded the "best fit" to the data, the Akaike Information Criteria (AIC) was computed for all models, and the model with the lowest AIC was considered to be the best fit to the data. Maximum likelihood estimates resulting from this analysis were squared to produce estimates of the variance due to each of the effects specified by the model (Neale $\&$ Maes, 1998). Univariate results for the scales of the PRF, and for the leadership and personality factor scores, may be found in Table 3. Only two of these variables (the PRF variables affiliation and order)

Table 3

MZ and DZ Correlations, and Genetic Analyses

\begin{tabular}{|c|c|c|c|c|c|c|}
\hline & $\mathrm{MZ}$ & $\mathrm{DZ}$ & $\mathrm{a}^{2}(95 \% \mathrm{CI})$ & $\mathrm{c}^{2}(95 \% \mathrm{CI})$ & $\mathrm{e}^{2}(95 \% \mathrm{CI})$ & AIC \\
\hline \multicolumn{7}{|l|}{ PRF Scale Scores } \\
\hline Abasement & .42 & .20 & $.41(.27-.56)$ & - & $.59(.48-.71)$ & -6.80 \\
\hline Achievement & .43 & -.01 & $.41(.26-.55)$ & - & $.59(.47-.70)$ & -1.71 \\
\hline Affiliation & .51 & .41 & - & $.49(.36-.64)$ & $.51(.42-.60)$ & -4.45 \\
\hline Aggression & .34 & .05 & $.33(.18-47)$ & - & $.67(.54-.80)$ & -6.95 \\
\hline Autonomy & .52 & .25 & $.54(.40-.70)$ & - & $.46(.37-.56)$ & -5.28 \\
\hline Change & .47 & .16 & $.45(.32-.61)$ & - & $.55(.45-.67)$ & -7.15 \\
\hline Cognitive Structure & .40 & -.05 & $.40(.25-.56)$ & - & $.60(.50-.75)$ & -0.68 \\
\hline Defendence & .42 & .32 & $.43(.29-.59)$ & - & $.57(.46-.69)$ & -4.63 \\
\hline Dominance & .53 & .19 & $.52(.38-.68)$ & - & $.48(.39-.59)$ & -6.63 \\
\hline Endurance & .40 & .07 & $.39(.25-.54)$ & - & $.61(.49-.73)$ & -6.47 \\
\hline Exhibition & .63 & .16 & $.61(.45-.74)$ & - & $.39(.31-.46)$ & -2.50 \\
\hline Harmavoidance & .61 & -.15 & $.60(.44-.76)$ & - & $.40(.32-.50)$ & 0.17 \\
\hline Impulsivity & .45 & .32 & $.30(.00-.58)$ & $.16(.00-.51)$ & $.54(.42-.64)$ & -5.58 \\
\hline Nurturance & .47 & .02 & $.46(.32-.62)$ & - & $.54(.44-.66)$ & 0.04 \\
\hline Order & .27 & .44 & - & $.31(.19-.45)$ & $.69(.57-.81)$ & -5.97 \\
\hline Play & .47 & .09 & $.46(.32-.62)$ & - & $.54(.44-.67)$ & -6.08 \\
\hline Sentience & .60 & .42 & $.61(.48-.78)$ & - & $.39(.32-.47)$ & -6.68 \\
\hline Social Recognition & .43 & .25 & $.43(.28-.57)$ & - & $.57(.46-.68)$ & -1.06 \\
\hline Succorance & .47 & .07 & $.45(.31-.60)$ & - & $.55(.44-.66)$ & -2.47 \\
\hline Understanding & .62 & .20 & $.61(.46-.75)$ & - & $.39(.31-.47)$ & -6.90 \\
\hline \multicolumn{7}{|l|}{ Factor Scores } \\
\hline Transformational Leadership & .58 & .21 & $.57(.42-.74)$ & - & $.43(.35-.54)$ & -6.75 \\
\hline Transactional Leadership & .47 & .33 & $.47(.33-.63)$ & - & $.53(.42-.64)$ & 3.97 \\
\hline Conscientiousness & .48 & .16 & $.48(.33-.62)$ & - & $.52(.42-.62)$ & -6.67 \\
\hline Extraversion & .66 & .22 & $.64(.50-.80)$ & - & $.36(.29-.44)$ & -2.37 \\
\hline Disagreeableness & .49 & .22 & $.48(.34-.62)$ & - & $.52(.42-.62)$ & -6.38 \\
\hline Neuroticism & .56 & .06 & $.55(.41-.74)$ & - & $.45(.38-.58)$ & 3.88 \\
\hline Openness to Experience & .69 & .26 & $.68(.54-.84)$ & - & $.32(.26-.39)$ & 0.04 \\
\hline
\end{tabular}

Note: Estimates are based on reduced best-fitting models.

Estimates indicated in italics represent a poor fit to the data. 
were best fit by models of determination that did not include genetic effects.

\section{Multivariate Genetic Analyses}

Genetic contributions to the relationship between leadership and personality were identified through the use of bivariate Cholesky decomposition. All variable pairs were fit with both an ACE and an AE model, and the model with the lowest AIC was considered to be the best fit to the data (Neale \& Maes, 1998). In all cases, AE models demonstrated better fit to the data. All bivariate correlations (zero-order phenotypic, genetic, and environmental) between the leadership and personality factors are presented in Table 4. The bivariate genetic and environmental correlations reported in this table were computed using Mx (Neale, 1997). Correlations in bold are significant at $p<.05$. Transformational leadership shows a statistically significant positive genetic correlation with conscientiousness, extraversion, and openness to experience. Transactional leadership shows a significant negative genetic correlation with conscientiousness and extraversion, and a significant positive genetic correlation with disagreeableness.

\section{Discussion}

Univariate genetic analyses of the personality dimensions confirm expectations from the literature (e.g., Plomin et al., 1990) that the basis of personality shows moderate to large genetic contributions. Of particular interest from the results presented herein, however, is the finding that there is a strong common source of genetic variation underlying leadership and personality - albeit not for all personality dimensions (neuroticism fails to demonstrate a significant genetic component after Cholesky decomposition). Transformational leadership shows a statistically significant positive genetic correlation with conscientiousness, extraversion, and openness to experience. Transactional leadership shows a significant negative genetic correlation with conscientiousness and extraversion, and a significant positive genetic correlation with disagreeableness.

Overall, results suggest that leadership (both transactional and transformational) and personality share a substantial amount of variation at the genetic level. It is of particular interest to note that conscientiousness and extraversion are negatively correlated with transactional leadership, suggesting that higher scores on the transactional leadership dimension correspond to disagreeableness, introversion, and a lack of conscientiousness. Given the genetically informative nature of the sample analyzed herein, the significant genetic correlations decomposed from these phenotypic relationships suggest that these characteristics may share common genetic origins. In other words, it is likely that the same gene(s) predisposing an individual to select a transactional leadership style, predispose an individual to be unconscientious, introverted, and disagreeable.

The present findings further highlight the difference between the two leadership styles. In particular, leaders who "transform" their followers and manage to motivate their employees to become dedicated and committed to their positions, are also outgoing, broad minded, and most likely respect their followers (high conscientiousness). In contrast, leaders who bargain with their employees for work to be accomplished, who manage by exception, and thus adopt a transactional style appear to have an opposite personality to those with a transformational style. By examining the personality traits that define the personality factors, the transactional leader is seen to be low in his/her need for achievement, does not stay on

\section{Table 4}

Bivariate Correlations (Phenotypic, Genetic, and Environmental) between PRF Factors and MLO Factors

\begin{tabular}{|c|c|c|c|c|}
\hline & Phenotypic & Genetic (95\% C.I.) & Specific Environment ( $95 \%$ C.I.) & AIC \\
\hline \multicolumn{5}{|c|}{ Bivariate Transformational Leadership Correlations } \\
\hline Conscientiousness & 0.43 & $0.58(0.42-0.73)$ & $0.20(0.06-0.34)$ & -19.365 \\
\hline Extraversion & 0.17 & $0.23(0.05-0.40)$ & $0.13(-0.02-0.27)$ & -20.029 \\
\hline Disagreeableness & 0.02 & $0.04(-0.17-0.25)$ & $-0.01(-0.16-0.13)$ & -18.423 \\
\hline Neuroticism & -0.02 & $0.02(-0.18-0.23)$ & $-0.04(-0.19-0.11)$ & -9.983 \\
\hline Openness to Experience & 0.45 & $0.56(0.41-0.70)$ & $0.25(0.10-0.39)$ & -9.360 \\
\hline \multicolumn{5}{|c|}{ Bivariate Transactional Leadership Correlations } \\
\hline Conscientiousness & -0.35 & $-0.49(-0.66--0.29)$ & $-0.19(-0.32 \tilde{n} \tilde{n} 0.05)$ & -10.253 \\
\hline Extraversion & -0.28 & $-0.46(-0.62--0.28)$ & $-0.07(-0.21-0.08)$ & -8.062 \\
\hline Disagreeableness & 0.18 & $0.23(0.01-0.44)$ & $0.07(-0.08-0.21)$ & -10.839 \\
\hline Neuroticism & 0.09 & $0.08(-0.1-0.30)$ & $0.08(-0.07-0.23)$ & 1.007 \\
\hline Openness to Experience & 0.10 & $0.12(-0.07-0.31)$ & $0.04(-0.10-0.19)$ & 1.414 \\
\hline
\end{tabular}

Note: Estimates are based on reduced best-fitting models.

Estimates indicated in italics represent a poor fit to the data.

Significant correlations are indicated in bold. 
course (i.e., has low endurance), is impulsive, disorganized, aggressive, dominant, and does not actively associate with others (i.e., has low affiliation).

\section{References}

Avolio, B., Bass, B. M., \& Jung, D. (1995). Construct validation and norms for the Multifactor Leadership Questionnaire (MLQ - Form 5X). CLS Report 95-4: Binghamton University: Centre for Leadership Studies.

Bass, B. M. (1985). Leadership: Good, better, best. Organizational Dynamics, 13(3), 26-40.

Bass, B. M. (1990). Bass \& Stogdill's handbook of leadership: Theory, research, and managerial applications (3rd ed.). New York, NY, USA: Free Press.

Bass, B. M., \& Avolio, B. (1991). Multifactor Leadership Questionnaire (Form 5X - Self). Palo Alto, CA: Consulting Psychologists Press.

Burns, J. H. (1978). Leadership. New York: Harper \& Row.

Jackson, D. (1987). Personality Research Form E Manual. London, ON: Research Psychologists Press.

James, W. (1880). Great men, great thoughts, and their environment. Atlantic Monthly, 46, 441-459.

James, W. (1890). The principles of psychology. New York: Henry Holt.

Johnson, A. M., Vernon, P. A., McCarthy, J. M., Molson, M., Harris, J. A., \& Jang, K. L. (1998). Nature vs nurture: Are leaders born or made? A behavior genetic investigation of leadership style. Twin Research, 1, 216-223.

Kasriel, J., \& Eaves, L. (1976). The zygosity of twins: Further evidence on the agreement between diagnosis by blood groups and written questionnaires. Journal of Biosocial Science, 8, 263-266.

Keller, T. (1999). Images of the familiar: Individual differences and implicit leadership theories. Leadership Quarterly, 10(4), 589-607.

Loehlin, J. C. (1992). Genes and environment in personality development. Newbury Park, CA, USA: Sage Publications, Inc.

McGue, M., \& Bouchard, T. J. J. (1984). Adjustment of twin data for the effects of age and sex. Behavior Genetics, 14, 325-343.

Neale, M. C. (1997). Mx: Statistical modeling (4th ed.). Richmond, VA: Department of Psychiatry, MCV.

Neale, M. C., \& Maes, H. M. (1998). Methodology for genetic studies of twins and families. Dordrecht: Kluwer Academic.

Nichols, R., \& Bilbro, W. (1966). The diagnosis of twin zygosity. Acta Genetica, 16, 265-275.

Plomin, R., DeFries, J. C., \& McClearn, G. E. (1990). Behavioral genetics: A primer (2nd ed.). New York, NY, USA: W. H.

Silverthorne, C. (2001). Leadership effectiveness and personality: A cross cultural evaluation. Personality and Individual Differences, 30(2), 303-309.

Stogdill, R. (1948). Personal factors associated with leadership: A survey of the literature. Journal of Psychology, 25, 35-71.

Vernon, P. A., McCarthy, J. M., Johnson, A. M., Jang, K. L., \& Harris, J. A. (1999). Individual differences in multiple dimensions of aggression: A univariate and multivariate genetic analysis. Twin Research, 2, 16-21. 